\title{
A Simplified Diagnosis Method for CHBMIs under Open-circuit Switch or Battery Faults
}

\author{
Omar Kherif, Tahar Zebbadji, Youcef Gherbi, Mohamed Larbi Azzouze, and Madjid Teguar
}

\begin{abstract}
This paper deals with the diagnosis of cascaded H-bridge multilevel inverters controlled by a sinusoidal level-shifted pulse-width modulation technique. For this purpose, the behaviour of 3, 5, 7 and 9-level inverters is studied for regular and faulty operation modes. Three types of recurring faults are considered, namely open-circuit of a switch, damaged and disconnected battery. Under a single fault, the output voltage signals are presented where the impact of each fault is discussed. In order to detect, identify and localise the three types of fault, a signal processing method is proposed, elaborating the output voltage of inverters with and without fault. The obtained results are convincing for the considered cases. The study shows no real correlation between the selected features from one to the other type of fault. Indeed, each fault type has its own trajectory with respect to the evolution of the output voltage characteristics. Thus, localizing the faulty component within the multilevel inverter can be made with no ambiguity. Such findings obviously solve a large part of problems associated with the presence of faults in multilevel inverters. They can help improving the reliability of the inverter in such way it continues working.
\end{abstract}

Keywords-Cascaded H-Bridge, Diagnosis, Multilevel inverter, Industrial electronics, Voltage source inverter.

\section{INTRODUCTION}

Multilevel inverters represent an ideal choice of the high-power demands for electric drives and renewable energies exploitation. These inverters might be considered as an important alternative in the area of high-power medium-voltage energy control with almost a high-quality output with low harmonic distortion [1]. Among many inverter's topologies, cascaded H-bridge multilevel inverter (CHBMI) presents an easier topology to implement with practically reduced harmonics [2]. CHBMIs are typically used to eliminate the bulky transformer required in the case of conventional multiphase inverters. These inverter also used to eliminate the clamping diodes and the flying capacitors required, respectively, in the case of diode and flying capacitor inverters [3,4]. However, these, on one hand, require a large number of isolated voltage sources to supply each cell and, on the other hand, the number of switches needed increases accordingly. Thus, the fault probability of the accompanying system raises $[5,6]$.

The reliability of CHBMI has received much attention from researchers due to the occurrence of various faults within the system (e.g., [7-10]). An unbalanced voltage is generated when a fault occurs which can produce permanent damage to the load

Manuscript received March 29,2021; revised August 2,2021.

$O$. Kherif is with The Advanced High Voltage Engineering Research Centre, School of Engineering, Cardiff University, CF243AA Cardiff, U.K. (e-mail: KherifO@cardiff.ac.uk).

T. Zebbadji, Y. Gherbi, M.L. Azzouze and M. Teguar are with Laboratoire de Recherche en Electrotechnique (LRE), Ecole Nationale Polytechnique, Algiers 16200, Algeria (e-mail: tahar.zebbadji@g.enp.edu.dz,youcef.gherbi@g.enp.edu.dz, mohamed_larbi.azzouze@g.enp.edu.dz).

Digital Object Identifier (DOI): 10.53907/enpesj.v1i2.23 or complete system failure [8]. Most of these faults occur in switching devices, circuit boards, capacitors, and power sources [11]. If these faults are not fixed, a considerable negative impact on the performance of the inverter and the system to which it is connected will be observed [11]. The thermal factor might be considered as a source of disturbance that has more impact on the reliability of power electronics components and systems with a rate of $55 \%$. Indeed, other factors such as humidity and vibrations are very often linked to the degradation of power devices [12].

In fact, CHBMI are currently utilized in an enormous variety of industrial applications, including variable speed AC drives. However, these inverters are quite susceptible to switch failures due to their complexity and exposure to several stresses [5]. According to [12], semiconductor defects account for $34 \%$ of failures in converter systems. Based on more than 200 products from 80 companies, semiconductor power devices were selected by $31 \%$ of respondents as being the most fragile components [12]. Capacitor faults include open-circuit/short-circuit, displacement of materials between electrodes creating a conductive path, dielectric breakdown, etc. [13]. In addition, PCB defects include broken metal pipes, corrosion or cracking of traces, misalignment of components, delamination of boards and cold welds [13].

Choi et al. [12] analysed the different methods of study and treatment of switch failures, giving statistics on this aspect. According to [8], on one hand, the short-circuit fault is difficult to handle because an abnormal over-current which can cause serious damage to other parts is produced immediately. On the other hand, the open-switch fault increases total harmonic distortion and adversely affects the grid, which is connected to. In literature, there is a great interest in detecting the faults that could occur in the controllable devices of multilevel inverters (e.g., [6, 14-16]). In [6] and [14], the detection method used a wavelet packet transform and a neural network algorithm without additional devices. Also, the current pattern by the 
open-switch fault of the two-level topology was used, in which, the detection method has been carried out using a differential equation of currents [15]. Therefore, most of the diagnostic methods for open-circuit faults have been practically focused on the occurrence of single faults. In addition, other works have the capability to handle and identify multiple failures (e.g., [10]). The average absolute values have been used here as prime quantities to formulate the diagnostic variables.

Indeed, any failure at a given level of the multi-level converter can cause abnormal operation of the electrical system. In electric drives, such a failure can cause the motor to overheat, increasing harmonics and acoustic noises, etc. Sometimes the need to shut down the entire drive system arises to avoid serious damage. To reduce downtime and therefore improve productivity, it is necessary to detect faults in converters in order to fix them [17]. It is well known that diagnosing faults in multilevel inverters is a difficult task requiring efficient and rapid decision-making procedures especially under extreme noisy measurement conditions, strongly interdependent data, large number of inputs and a complex interaction between symptoms and faults [1]. The diagnosis consists in locating the fault, and this, by comparing the current state of the system according to the readings of the sensors compared to that of normal operation [18]. Better understanding of the system dynamics might be a key factor that leads to a successful application, decreasing losses and improving the quality of the output voltage waveforms.

In this paper, simulation tests have been carried out to study a CHBMI under different possible faults. One switching device within the inverter has been affected by open-circuit faults. Also, the malfunction or disconnection of one DC link has been considered. Based on the output voltage records, the effects of the selected faults have been examined and the output voltage has been presented accordingly. The obtained results show the possibility to visually distinguish the fault features compared with the regular operation mode. Using the output voltages, THD, $a_{0}, A_{f}$, RMSE and STD have been used to extract information corresponding to the fault detection, identification and localisation. The obtained results confirm the effectiveness of the proposed fault diagnostic approach for 3, 5, 7, and 9-level inverters. Diagnostic results and the information on the identified faulty switches and batteries in multilevel converters can help to reduce the downtime cost of industrial power electronic systems.

\section{INVERTER TOPOLOGY AND CONTROL STRATEGY}

\section{A. CHBMI Topology}

Fig. 1 shows the circuit configuration of the selected threephases power-conversion multilevel inverter.

The circuit has $N$-number of $\mathrm{H}$-Bridge per phase, providing approximately a sinusoidal output voltage. For each phase, this later is the sum of the voltages that are generated by each cell. A given $\mathrm{H}$-Bridge has been made up of four switches namely $S_{1 i}, S_{3 i}, S_{2 i}$ and $S_{4 i}$, having an independent DC voltage source $V_{\text {in }}=E=E_{i}$.

The output voltage phase is synthesized by the sum of inverter outputs. Each single-phase full bridge inverter can generate three level outputs, $+E, 0$, and $-E$. This is made possible

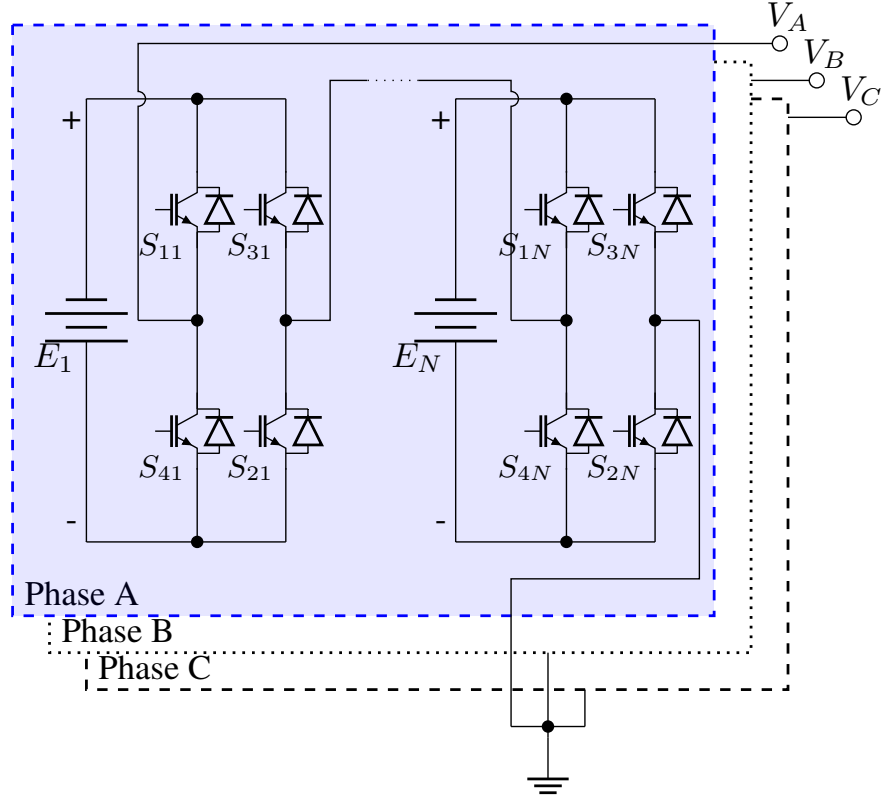

Fig. 1: Circuit configuration of the three-phase CHBMI

by connecting the DC sources sequentially to the AC side via the four semiconductor power devices. Fig. 2 illustrates the voltage polarities according to the switching states for each $\mathrm{H}$ bridge(positive, zero and negative polarities in Figs. 2(a), 2(b) and 2(c), respectively).

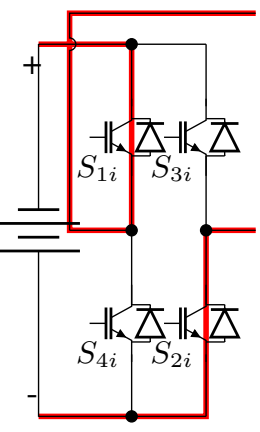

(a) Positive polar-(b) Zero polarity ity

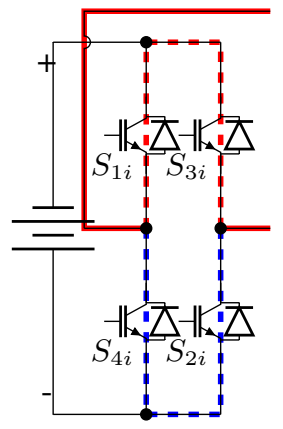

(c) Negative polarity

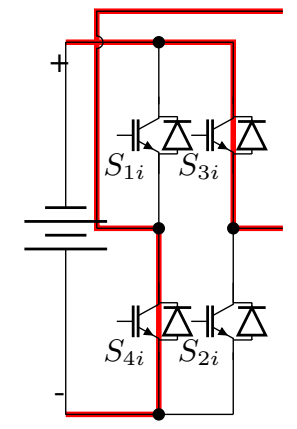

Fig. 2: Output voltage polarities for each H-bridge

From Fig. 2, a positive polarity is obtained for the case where $S_{1 i}$ is activated and $S_{3 i}$ is deactivated. The negative polarity appears for the complementary case. Moreover, the zero polarity is obtained during the simultaneous activation or deactivation of the switches $\left(S_{1 i}\right.$ and $\left.S_{3 i}\right)$. Table I summarizes the switching states of the 3-level inverter (only one $\mathrm{H}$ bridge). It is worth noting that the state of switch is designted by 1 or 0 when it is on ON-state or OFF-state, respectively.

For 5, 7 and 9-level inverter, a second, third and fourth block (bridge $\mathrm{H}$ ) are added in cascade per phase, respectively. Each inverter will have the same three voltage levels, namely $+E$, 0 and $-E$ for every cycle. By cascading the output voltage of the H-bridge inverters per phase, a stepped voltage waveform is produced. It is well known that the level number of the output voltage is defined by $m=2 s+1$, in which $s$ is the number of DC sources or the cascaded H-bridges per leg. It is worth noting that the three output voltages of the three-phase cascaded 
Table. I

SWITCHING STATES OF A H-BRIDGE INVERTER

\begin{tabular}{clr}
\hline Output voltage & \multicolumn{2}{r}{ Switching states } \\
\cline { 2 - 3 } $\mathbf{V}_{\mathbf{A}}$ & $\mathbf{S}_{\mathbf{1}}$ & $\mathbf{S}_{\mathbf{3} \mathbf{i}}$ \\
\hline $\mathrm{E}$ & 1 & 0 \\
0 & 1 & 1 \\
0 & 0 & 0 \\
$-\mathrm{E}$ & 0 & 1 \\
\hline
\end{tabular}

inverters can be connected in either wye or delta connection. The line voltage is equal to the phase voltage in delta connection. However, the line voltage is obtained by subtracting two phase voltages in wye connection. In this topology, the maximum number of levels is $m=4 s+1$ and triplen harmonics are eliminated.

\section{B. Control and Modulation Strategy}

Multi-carrier PWM method is embraced in this investigation to achieve an approximately sinusoidal output voltage waveform per phase. In this method, PWM signals are generated by comparing a reference signal of sinusoidal form with triangular carriers. Three sinusoidal signals, shifted by $(2 \pi / 3)$-angle, are required for the three output voltages. Recall that for an inverter of $N$ levels, there must be $(N-1)$ triangular carriers with the same frequency and amplitude, constituting the level shifted PWM (LS-PWM). Fig. 3 shows an example of the control signals for generating the pulses of the switches of a 5-level CHBMI, in which a switching frequency $F_{c}=1 k H z$ has been selected with a modulation ratio $M_{i}=1$.

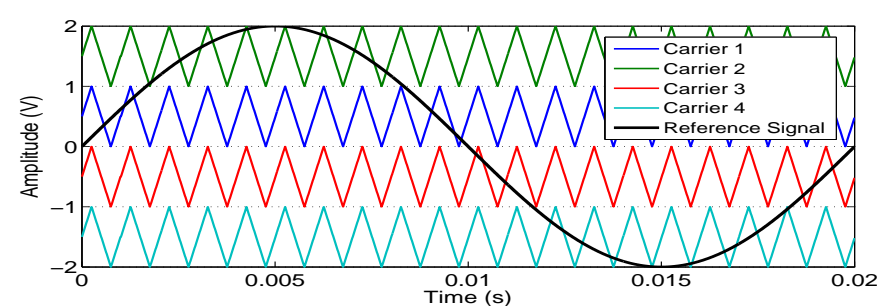

Fig. 3: PWM strategy for the 5-level CHBMI

Phase disposition strategy is used for the carrier arrangements (i.e., in phase with each other), which have the same peak to peak amplitude and $F_{c}$ frequency. In this modulation technique, the sinusoidal reference is constantly compared with each of the triangular signals. If the reference is greater than the triangular signal, the switch corresponding to this modulation is active. Otherwise, the switch in question is in the ON state. For each sine signal, four features are obtained with respect to the four carriers. Fig. 4 illustrates an example of the triggering pulses obtained for the 5-level CHBMI.

\section{FAulty Operation Mode Results}

In this section, regular and faulty operation modes of the threephase 3, 5, 7 and 9-level CHBMI have been presented. Each inverter has been simulated in MATLAB environment to assess the proposed fault detection technique. DC voltage sources of $30 \mathrm{~V}$ have been considered with a fundamental frequency $(f)$ of $50 \mathrm{~Hz}$ and sampling $\left(f_{s}\right)$ of $5 \mathrm{kHz}$.

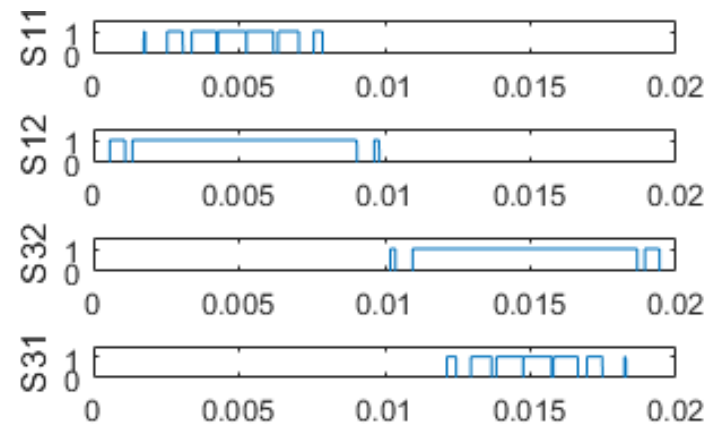

Fig. 4: Triggering pulses for the 5-level CHBMI

\section{A. Open-Circuit Fault (Type I)}

In this part, simulations have been carried out to show the effect of switches' open-circuit faults on the inverter output voltages. Fig. 5 shows the output voltage patterns, recorded for fault of one selected switch in the considered inverter. Figs. 5(a), 5(b), 5(c) and 5(d) show the effect of open-fault in CHBMI of 3, 5, 7, and 9 levels, respectively.

For regular operation mode (Fig. 5), each output voltage can be represented by Fourier series, in which the waveform is given as follows:

$$
V(t)=\sum_{n=1}^{\infty} V_{n} \sin (n \omega t), \quad \omega=2 \pi f
$$

where, $V_{n}$ is the amplitude of $n$-th voltage harmonic that is given by:

$$
V_{n}= \begin{cases}\frac{4}{n \pi} \sum_{k=1}^{s} V_{d c} \cos \left(n \alpha_{k}\right) & \text { for odd } \mathrm{n} \\ 0 & \text { for even } \mathrm{n}\end{cases}
$$

in which, $s$ is the number of H-bridges and $\alpha_{k}$ is the switching angle used in the study $(2 \pi / 3)$.

Compared to the regular operation mode, one can see that all fault features in open-circuit cases could be visually detected. Fault in a particular switch within a given leg leads to a deformation on the output voltage of the corresponding phase related to this leg. For a single H-bridge, the failure of a switch causes the disappearance of the positive or negative part of the output voltage. The distorted output signal due to the open circuit type fault of switch $S_{11}$ is exactly the same as that of $S_{21}$ where only the negative part of the signal appeared. Regarding a fault at switch $S_{31}$ or $S_{41}$ (they have the same waveform), the output voltage contains only the positive part of the signal associated with regular operation. Therefore, only one spectrum can be found, describing the open circuit fault in a 3-level inverter as shown in Fig. 5(a)

Referring to the results of Fig. 5(b), three types of deformations have been noticed at the level of the output signal: two waveforms for a fault in $H_{1}$ and another waveform for $H_{2}$. The first one consist in the absence of $\pm 2 E( \pm 60 \mathrm{~V})$ levels in some intervals. For the second voltage waveform, there is a disappearance of $\pm E( \pm 30 \mathrm{~V})$ levels with zero voltage levels during a time interval greater than half period. The complete absence of either positive or negative sequences is characterising the third waveform. Indeed, a type I fault of $S_{11}$ and $S_{31}$ brings out the same 


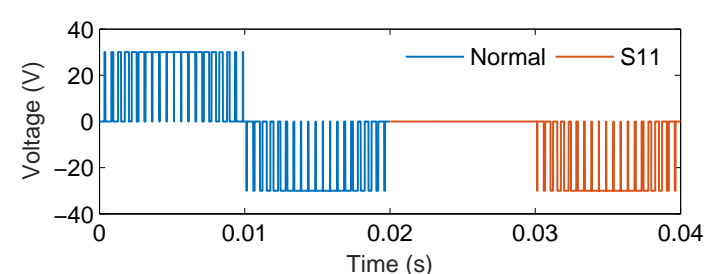

(a) 3-level

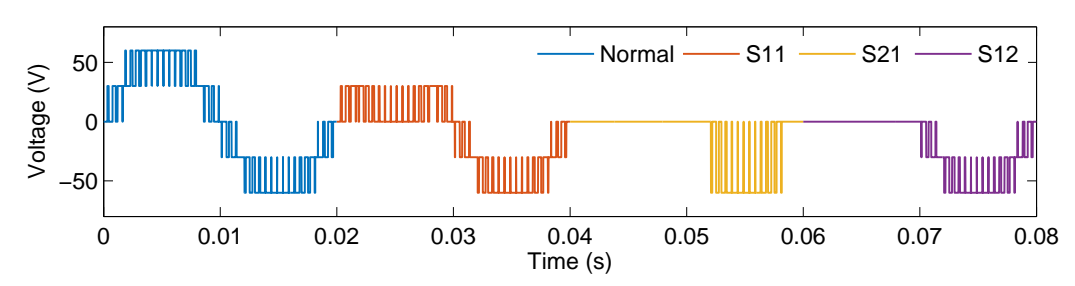

(b) 5-level

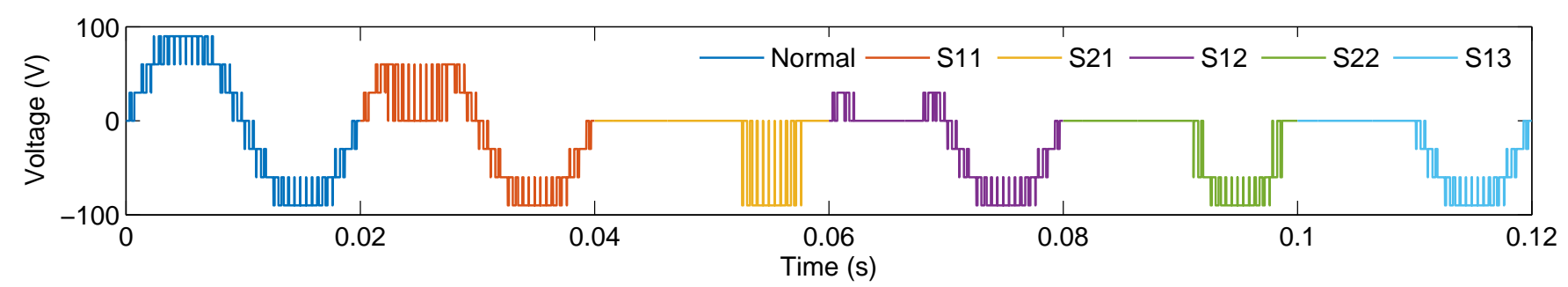

(c) 7-level

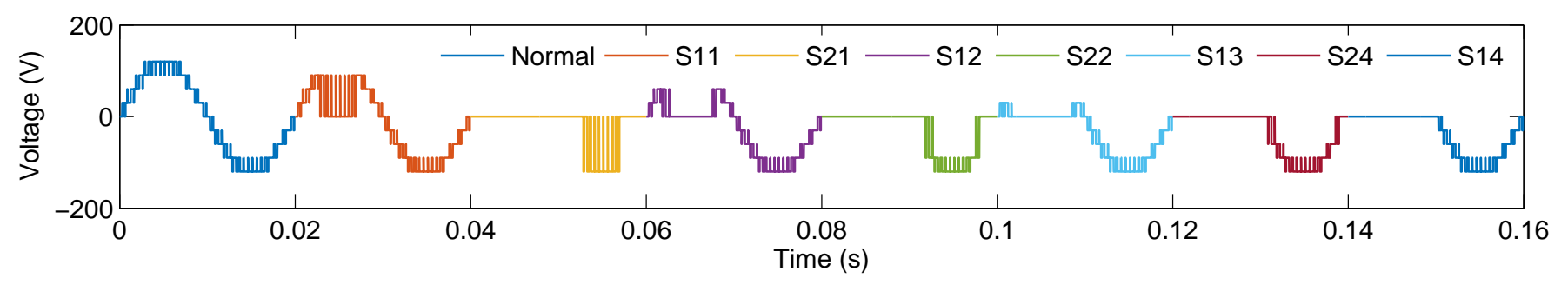

(d) 9-level

Fig. 5: Output voltage of the 3, 5, 7 and 9-level inverters during a type I fault and normal operation mode

waveform with symmetrical characteristics with respect to the time axis. The same observation is perceived for the following pairs of switches: $\left(S_{41}\right.$ and $\left.S_{21}\right),\left(S_{12}\right.$ and $\left.S_{32}\right)$ and $\left(S_{22}\right.$ and $S_{42}$ ). It should be noted that the waveform obtained for a type I fault of $S_{12}$ and $S_{22}$ are identical. Thus, if we consider the spectrum of the output voltage signal, three waveforms can be identified: the first waveform concerns the switches $S_{11}$ and $S_{31}$, the second one is related to those of $S_{21}$ and $S_{41}$ and the last one is linked to those of $S_{12}, S_{22}, S_{32}$, and $S_{42}$.

From the results of Figs. 5(c) and 5(d), one can generalize the study to an $N$-level inverter system according to the output signals associated to a type I fault of a given switch. In this condition, a number $(N-2)$ of signal waveforms is obtained for an $N$-level inverter. Thereafter, the waveforms for each $\mathrm{H}$-bridge are briefly described as follows:

\section{Type I fault on $H_{1}$ :}

- In the switch $S_{11}\left(S_{31}\right.$ respectively): The deformation consists in the disappearance of the last level $(N-1) E / 2$ in the positive (negative respectively) cap. In addition, during the interval where $S_{11}\left(S_{31}\right.$ respectively) is active, the voltage levels vary from 0 to $((N-1) / 2-1) E$ in the positive (negative respectively) cap.

- In the switch $S_{41}\left(S_{21}\right.$ respectively): The output voltage is zero except for the operating interval of $S_{11}$ ( $S_{31}$ respectively) where it varies directly between 0 and $(N-1) E / 2$.
2. Type I fault on $H_{i}$ :

- In the switch $S_{1 i}\left(S_{3 i}\right.$ respectively): The voltage is null during the ON-state interval of $S_{1 i}\left(S_{3 i}\right.$ respectively).

- In the switch $S_{4 i}\left(S_{2 i}\right.$ respectively): The voltage is null during the whole period except the ON-state interval of $S_{1 i}\left(S_{3 i}\right.$ respectively).

3. Type I fault on $H_{N}$ : The distorted output voltage following the appearance of a fault in $S_{1 n}$ is exactly the same as that in $S_{2 n}$. The same observation is obtained for the two other switches $\left(S_{3 n}\right.$ and $\left.S_{4 n}\right)$. These two signals are also symmetrical with respect to the time axis with a phase shift of $\pi$.

\section{B. Battery Fault Type II}

Under particular conditions such as the batteries ageing, a DC source might be lost. The effect of such a fault has been investigated in this part where the internal resistor has been neglected. Fig. 6 shows the output voltages of the 9-level inverter such that the bridges $H_{1}, H_{2}, H_{3}$ and $H_{4}$ are in sequence way one after one under the type II fault.

In this figure, the obtained four signals can be overlapped to clarify the difference between the defected batteries. A common result between these four signals is the loss of the last level of voltage $(N-1) E / 2(4 E$ in this case). It is true that there are 3 levels of voltage left, however, the arrangement of the remaining 


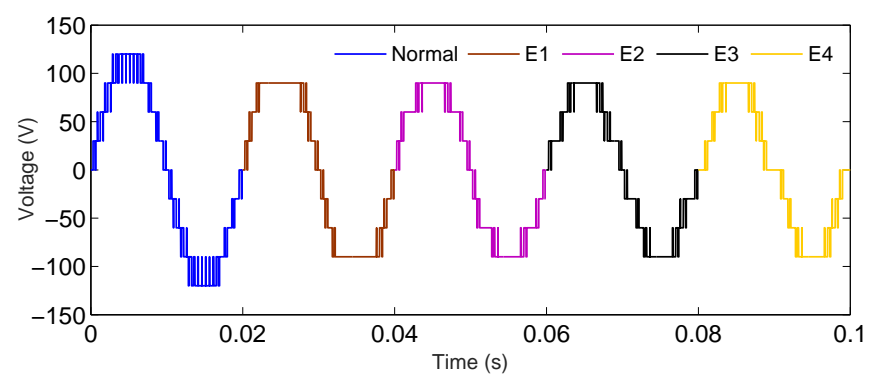

Fig. 6: Output voltages under type II fault in the CHBMI

levels is different. One can notice that a type II fault on the $H_{1}$ bridge, the $120 \mathrm{~V}$ level is replaced by the one of $90 \mathrm{~V}$. A type II fault affecting the $\mathrm{H}_{2}$ bridge generates the same waveform of signal found previously but with a slight decrease in the duration of the $90 \mathrm{~V}$ level. For the fault concerning the $H_{3}$ bridge, we note that the duration of the $60 \mathrm{~V}$ level has decreased slightly compared to that of the fault of the $\mathrm{H}_{2}$ bridge. Whereas, for the fault concerning bridge $H_{4}$, the duration of the $30 \mathrm{~V}$ level has decreased compared to that of the fault of bridge $H_{3}$. This means that the duration of each level is directly linked to the fault affecting a given bridge $\left(H_{i}\right)$. This duration can be quantified by the control sequences of the different switches of a given bridge (see Fig. 6).

\section{Battery Fault Type III}

In this part, the battery of a given bridge is totally disconnected, hence, open-circuit at the input side of this bridge is obtained. Fig. 7 shows the $V_{A N}$ output voltages of the 9-level inverter respectively for a fault in the battery disconnection of $H_{1}, H_{2}$, $\mathrm{H}_{3}$ and $\mathrm{H}_{4}$.

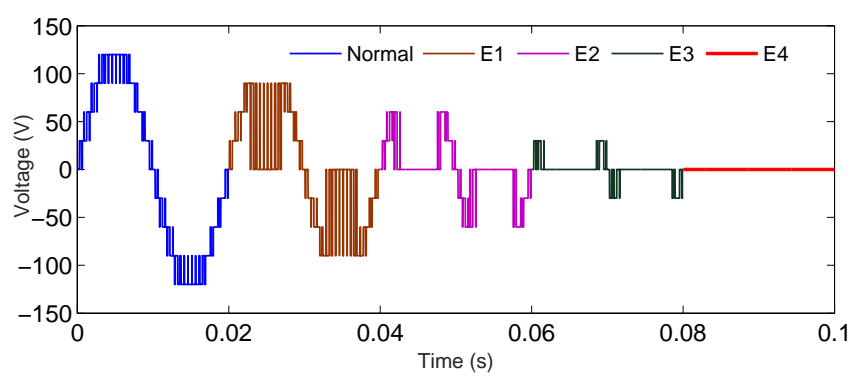

Fig. 7: Output voltages under type III fault in the CHBMI

Each battery contributes in a different way depending on its order of connection within the multilevel inverter. This means that the time contribution for each level is different from the other (see Fig. 7). Disconnecting a battery from a given bridge completely opens the phase for a well-defined period. By disconnecting the battery from the $H_{1}$ and for a modulation index equal to the unit, we notice the same phenomenon as that obtained for a simultaneous type I fault of $S_{11}$ and $S_{31}$. Likewise, a type III fault affecting the $H_{i}$ bridge is equivalent to a simultaneous type I fault of the switches $S_{1 i}$ and $S_{3 i}$. By disconnecting the battery from the $H_{n}$ bridges, one can notice that during the application of its own voltage $E$, the output voltage $\left(V_{A N}\right)$ is null. It can be noted that the application duration of the voltage $E$ associated to $\mathrm{H}_{4}$ is observed throughout the period. Therefore, the voltage $V_{A N}$ is null for the entire duration of the type III fault.

\section{Fault Diagnosis Method}

\section{A. Features Extraction Technique}

In this section, a signal processing technique is presented, allowing the analysis of electrical signals in order to extract information useful for the detection and characterization of type faults (I, II and III). This method is based on the frequency decomposition of the signals, and this allows computing the THD, the mean value, the standard deviation and the root mean square error of the signals to be analysed in MATLAB environment. The frequency spectrum of a signal has been computed with and without faulty operation. Thereafter, the different parameters have been calculated.

Fourier series decomposition helps with the computation of the signal THD and the fundamental amplitude, which describe the quality of the output waveform. The signal mean value of the output voltage is the average of the instantaneous values measured over a full period, corresponding to the first component of the signal FFT. In addition, the standard deviation indicates the degree of variation or dispersion compared to the average (average or expected value). A low standard deviation indicates that the data points tend to be very close to the mean, while a high standard deviation indicates that the data is spread over a wide range of values.

\section{B. Features Extraction Results for Type I Fault}

1-Type I Fault in 3-level CHBMI: For the 3-level inverter, Table II illustrates the computed values of the parameters used in this study. These parameters have been calculated with and without a faulty operation.

Table. II

FEATURES OF THE 3-LEVEL INVERTER UNDER TYPE I FAULT

\begin{tabular}{c|c|c|c|c|c}
\hline $\begin{array}{c}\text { Operation } \\
\text { with/without } \\
\text { type I fault }\end{array}$ & $\begin{array}{c}\text { THD } \\
(\boldsymbol{\%})\end{array}$ & $\begin{array}{c}\mathbf{A}_{\mathbf{f}} \\
(\mathrm{V})\end{array}$ & $\begin{array}{c}\mathbf{a}_{\mathbf{0}} \\
(\boldsymbol{\%})\end{array}$ & STD & $\begin{array}{c}\text { RMSE } \\
(\boldsymbol{\%})\end{array}$ \\
\hline Without & 52.36 & 29.99 & 0 & 23.93 & 0 \\
\hline$S_{11}$ or $S_{21}$ & 85.87 & 14.99 & -63.68 & 13.97 & 29.25 \\
\hline$S_{31}$ or $S_{41}$ & 85.87 & 14.99 & +63.68 & 13.97 & 29.25 \\
\hline
\end{tabular}

From Table II, the results show remarkable differences between the values obtained during regular operation mode and that under fault. Indeed, the fault of one open-circuit switch generates a remarkable increase in THD from $52.36 \%$ to $85.87 \%$, accompanied by a decrease in the amplitude of the fundamental (denoted $A_{f}$ ) from $29.99 \mathrm{~V}$ to $14.99 \mathrm{~V}$. This is to say that this fault generates a strong voltage distortion. In addition, this anomaly causes an increase of the relative error of the output voltage signal, up to $29.25 \%$. Moreover, a decrease in the standard deviation of the signal from 23.93 to 13.97 was recorded. In faultless operation of the inverter, the voltage signal is characterized by its null mean value. The type I fault generates a signal distortion for the $S_{11}$ and $S_{21}$ switches symmetrically compared to that of $S_{41}$ and $S_{31}$, that is why the same mean output voltage value; having opposite signs, has been obtained.

From the disparities between the obtained results, it is concluded that the selected features are capable of detecting and locating the fault by indicating the opening of a switch on the same path, 
i.e., $S_{11}$ or $S_{21}$ on one hand, or $S_{31}$ or $S_{41}$ on the other hand, without indicating the exact position of the open-circuit switch.

2- Type I Fault in 5-level CHBMI: In the case of 5-level inverter, Table III illustrates the different values of the features used during this investigation.

Table. III

FEATURES OF THE 5-LEVEL INVERTER UNDER TYPE I FAULT

\begin{tabular}{c|c|c|c|c|c}
\hline $\begin{array}{c}\text { Operation } \\
\text { with/without } \\
\text { type I fault }\end{array}$ & $\begin{array}{c}\text { THD } \\
(\%)\end{array}$ & $\begin{array}{c}\mathbf{A}_{\mathbf{f}} \\
(\mathrm{V})\end{array}$ & $\begin{array}{c}\mathbf{a}_{\mathbf{0}} \\
(\boldsymbol{\%})\end{array}$ & STD & $\begin{array}{c}\text { RMSE } \\
(\boldsymbol{\%})\end{array}$ \\
\hline Without & 26.91 & 60.10 & 0 & 43.99 & 0 \\
\hline$S_{11}$ & 67.89 & 36.53 & -35.93 & 31.22 & 23.01 \\
\hline$S_{31}$ & 67.89 & 36.53 & +35.93 & 31.22 & 23.01 \\
\hline$S_{21}$ & 110.54 & 23.52 & -55.73 & 24.79 & 36.26 \\
\hline$S_{41}$ & 110.54 & 23.52 & +55.73 & 24.79 & 36.26 \\
\hline$S_{12}$ or $S_{22}$ & 57.72 & 30.05 & -63.68 & 24.52 & 24.52 \\
\hline$S_{32}$ or $S_{42}$ & 57.72 & 30.05 & +63.68 & 24.52 & 24.52 \\
\hline & & & & &
\end{tabular}

According to the results of Table III, the operating mode with an anomaly can be detected when the THD value is greater than $26.91 \%$. The fault in this case can be classified into 3 groups, corresponding to the three waveforms of signals shown in Fig. 5(b). The first group represents a fault in the lower switches of $H_{1}\left(S_{41}\right.$ and $\left.S_{21}\right)$ with a THD of $110.54 \%$. The second group characterises a fault in the upper switches $\left(S_{11}\right.$ and $S_{31}$ ) of $H_{1}$ with a THD of $67.89 \%$. Finally, the third group is related to an open-circuit fault in all switches of $\mathrm{H}_{2}$, having a THD of $57.72 \%$. Regarding the sign of the mean value (positive or negative), one can locate the faulty switch within the three given groups as follows:

- Group 1: positive value means that the fault is on $S_{41}$, otherwise $S_{21}$.

- Group 2: positive value means that the fault is on $S_{31}$, otherwise it is on $S_{11}$.

- Group 3: positive (respectively negative) value means that the fault is on $S_{42}$ or $S_{32}$ (respectively $S_{12}$ or $S_{22}$ ).

In general, the followed approach allows locating the default position of the switch, with the exception of the last bridge $\left(\mathrm{H}_{2}\right)$ where it is possible to distinguish between the pairs of switches $\left(S_{12}\right.$ or $\left.S_{22}\right)$ and $\left(S_{42}\right.$ or $\left.S_{32}\right)$.

3- Type I Fault in 7-level CHBMI: Table IV summarizes the different values of the proposed features for the 7-level inverter with and without type I defect.

The difference in THD values allows identifying four groups of switches. The group 1, made up of the switches $S_{41}$ and $S_{21}$, stands out with a THD of $130.51 \%$. The signals whose THD is $62.63 \%$ (default on $S_{11}$ and $S_{31}$ with the upper switches of the bridge $\mathrm{H}_{2}$ ) compose the group 2. For a fault in the lower switches of $\mathrm{H}_{2}$, the THD is $69.84 \%$. The group 4 concerns the fault of all the switches of $H_{3}$, which is characterised by a THD of $50.56 \%$.
Table. IV

FEATURES OF THE 7-LEVEL INVERTER UNDER TYPE I FAULT

\begin{tabular}{c|c|c|c|c|c}
\hline $\begin{array}{c}\text { Operation } \\
\text { with/without } \\
\text { type I fault }\end{array}$ & $\begin{array}{c}\text { THD } \\
(\boldsymbol{\%})\end{array}$ & $\begin{array}{c}\mathbf{A}_{\mathbf{f}} \\
(\mathrm{V})\end{array}$ & $\begin{array}{c}\mathbf{a}_{\mathbf{0}} \\
(\boldsymbol{\%})\end{array}$ & $\mathbf{S T D}$ & $\begin{array}{c}\text { RMSE } \\
(\boldsymbol{\%})\end{array}$ \\
\hline Without & 18.26 & 89.92 & 0 & 64.63 & 0 \\
\hline$S_{11}$ & 60.94 & 60.48 & -26.16 & 50.06 & 18.80 \\
\hline$S_{31}$ & 60.94 & 60.48 & +26.16 & 50.06 & 18.80 \\
\hline$S_{21}$ & 130.51 & 29.50 & -53.65 & 34.25 & 41.67 \\
\hline$S_{41}$ & 130.51 & 29.50 & +53.65 & 34.25 & 41.67 \\
\hline$S_{12}$ & 62.63 & 47.31 & -53.25 & 39.47 & 27.57 \\
\hline$S_{32}$ & 62.63 & 47.31 & +53.25 & 39.47 & 27.57 \\
\hline$S_{22}$ & 69.84 & 42.63 & -59.11 & 36.76 & 31.07 \\
\hline$S_{42}$ & 69.84 & 42,63 & +59.11 & 36.76 & 31.07 \\
\hline$S_{13}$ or $S_{23}$ & 50.56 & 44,95 & -63.68 & 35.63 & 29.29 \\
\hline$S_{33}$ or $S_{43}$ & 50.56 & 44.95 & +63.68 & 35.63 & 29.29 \\
\hline
\end{tabular}

At this point, one can use the other parameters such as the fundamental amplitude, the absolute value of the DC component, STD or RMSE to obtain two complementary subgroups (belong to the group 2). The first subgroup 2.1 is formed by the upper switches of $H_{1}\left(S_{11}\right.$ and $\left.S_{31}\right)$ whose fundamental value is equal to $60.48 \mathrm{~V}$. The subgroup 2.2 contains the two switches of $\mathrm{H}_{2}\left(\mathrm{~S}_{42}\right.$ and $\left.\mathrm{S}_{22}\right)$ with the fundamental value of around 40V. Moreover, to distinguish between the switches of each group/subgroup, the sign of the mean values has been elaborated as follows:

- Group 1: positive (respectively negative) value means that the fault is on $S_{41}$ (respectively $S_{21}$ ).

- Subgroup 2.1: positive value means that the default is on $S_{41}$, otherwise $S_{21}$.

- Subgroup 2.2: positive value means that the default is on $S_{32}$, otherwise it is on $S_{12}$.

- Group 3: positive value means that the default is on the switch $S_{42}$, otherwise it is on $S_{22}$.

- Group 4: positive value indicates that the fault is on $S_{43}$ or $S_{33}$, otherwise it is on $S_{13}$ or $S_{23}$.

It is important to note that this approach requires more precision to distinguish between either the switches of subgroups 2.1 and 2.2 or the pairs $\left(S_{13}\right.$ or $\left.S_{23}\right)$ and $\left(S_{33}\right.$ or $\left.S_{43}\right)$ due to the fact that the parameters values are close to each other.

4-Type I Fault in 9-level CHBMI: Table V illustrates the different values of the parameters used for the 9-level inverter for the type I fault.

Based on the results of the computed THD, five groups of switches can be obtained as follows:

- Group 1 is associated to a fault on $S_{41}$ and $S_{21}$, which has a THD of $145.22 \%$. 
Table. V

FEATURES OF THE 9-LEVEL INVERTER UNDER TYPE I FAULT

\begin{tabular}{c|c|c|c|c|c}
\hline $\begin{array}{c}\text { Operation } \\
\text { with/without } \\
\text { type I fault }\end{array}$ & \multicolumn{6}{|c}{$\begin{array}{c}\text { THD } \\
(\mathbf{\%})\end{array}$} & $\begin{array}{c}\mathbf{A}_{\mathbf{f}} \\
(\mathrm{V})\end{array}$ & $\begin{array}{c}\mathbf{a}_{\mathbf{0}} \\
(\boldsymbol{\%})\end{array}$ & $\mathbf{S T D}$ & $\begin{array}{c}\text { RMSE } \\
(\boldsymbol{\%})\end{array}$ \\
\hline Without & 13.83 & 120 & 0 & 85.64 & 0 \\
\hline$S_{11}$ & 56.61 & 85.47 & -21.27 & 69.44 & 16.18 \\
\hline$S_{31}$ & 56.61 & 85.47 & +21.27 & 69.44 & 16.18 \\
\hline$S_{21}$ & 145.22 & 34.51 & -52.68 & 43.02 & 45.47 \\
\hline$S_{41}$ & 145.22 & 34.51 & +52.68 & 43.02 & 45.47 \\
\hline$S_{12}$ & 64.52 & 66.91 & -45.03 & 56.31 & 25.43 \\
\hline$S_{32}$ & 64.52 & 66.91 & +45.03 & 56.31 & 25.43 \\
\hline$S_{22}$ & 81.75 & 53.07 & -56.77 & 48.47 & 33.36 \\
\hline$S_{42}$ & 81.75 & 53.07 & +56.77 & 48.47 & 33.36 \\
\hline$S_{13}$ & 56.08 & 61.23 & -58.36 & 49.64 & 28.58 \\
\hline$S_{33}$ & 56.08 & 61.23 & +58.36 & 49.64 & 28.58 \\
\hline$S_{23}$ & 58.51 & 58.75 & -60.83 & 48.13 & 30.01 \\
\hline$S_{43}$ & 58.51 & 58.75 & +60.83 & 48.13 & 30.01 \\
\hline$S_{14}$ or $S_{24}$ & 47.65 & 59.99 & -63.69 & 46.99 & 29.29 \\
\hline$S_{34}$ or $S_{44}$ & 47.65 & 59.99 & +63.69 & 46.99 & 29.29 \\
\hline & \multicolumn{5}{|c|}{}
\end{tabular}

- Group 2 represents an open-circuit fault of the upper switches of $H_{1}\left(S_{11}\right.$ and $\left.S_{31}\right)$ and all those of $H_{3}$ where the THD is around $57 \%$.

- Group 3 characterises faults in the upper switches of $H_{2}$ $\left(S_{12}\right.$ and $S_{32}$ ) with a THD equal to $64.52 \%$.

- Group 4, having THD equal to $81.75 \%$, is related to faults of the lower switches of $\mathrm{H}_{2}\left(S_{42}\right.$ and $\left.S_{22}\right)$.

- Group 5 is linked to open-circuit of the $H_{4}$ with a THD of $47.65 \%$.

It is worth noting that each group contains at least 2 switches. To overcome the localisation problem, the maximum value of the fundamental, the absolute value of the DC component, STD and RMSE have been exploited. For instance, as with the 7level inverter, the sign of the mean values $\left(a_{0}\right)$ might be used as follows :

- Group 1: positive value of $a_{0}$ means that the fault is on $S_{41}$, otherwise it is on $S_{21}$.

- Group 2 : this group, containing 6 switches, has been subdivided into the following subgroups :

- Subgroup 2.1: positive (respectively negative) value of 52.68V means that the fault is on $S_{41}$ (respectively $\left.S_{21}\right)$.

- Subgroup 2.2: positive (respectively negative) mean value of $58.36 \mathrm{~V}$ concerns fault is on $S_{33}$ (respectively $S_{13}$ ).

- Subgroup 2.3: this subgroup is identified by mean value of $60.83 \mathrm{~V}$, which is related to a fault on $S_{43}$ (respectively $S_{23}$ ) if its sign is positive (respectively negative).
- Group 3: positive value of $a_{0}$ means that the fault is on $S_{32}$, otherwise it is $S_{12}$.

- Group 4: positive (respectively negative) value of $a_{0}$ indicates that the fault is on $S_{42}$ (respectively $S_{22}$ ).

- Group 5: positive value of $a_{0}$ means that the fault is on $S_{43}$ or $S_{34}$, otherwise, it is on $S_{14}$ or $S_{24}$.

\section{Features Extraction Results for Type II Fault}

The same aforementioned features have been taken into account to deal with the fault localisation of a faulty battery in a 9level inverter. The extracted features have been computed and illustrated in Table VI.

Table. VI

FEATURES OF THE 9-LEVEL INVERTER UNDER TYPE II FAULT

\begin{tabular}{c|c|c|c|c|c}
\hline $\begin{array}{c}\text { Operation } \\
\text { with/without } \\
\text { type II fault }\end{array}$ & $\begin{array}{c}\text { THD } \\
(\boldsymbol{\%})\end{array}$ & $\begin{array}{c}\mathbf{A}_{\mathbf{f}} \\
(\mathrm{V})\end{array}$ & $\begin{array}{c}\mathbf{a}_{\mathbf{0}} \\
(\boldsymbol{\%})\end{array}$ & $\mathbf{S T D}$ & $\begin{array}{c}\text { RMSE } \\
(\boldsymbol{\%})\end{array}$ \\
\hline Without & 13.83 & 120 & 0 & 85.64 & 0 \\
\hline$E_{1}$ & 16.86 & 102.7 & 0 & 73.65 & 13.99 \\
\hline$E_{2}$ & 19.15 & 90.35 & 0 & 65.05 & 24.05 \\
\hline$E_{3}$ & 19.90 & 84.67 & 0 & 61.04 & 28.72 \\
\hline$E_{4}$ & 24.40 & 82.19 & 0 & 59.82 & 30.15 \\
\hline
\end{tabular}

According to this table, one can observe that the mean value is null for all cases of this type of fault. This observation is due to the fact that the signals extracted after the appearance of a fault always remain symmetrical with respect to the time axis. This parameter no longer fits into the fault localisation. From the THD readings, the type II fault of battery $E_{1}$ and $E_{4}$ can be easily detected because their respective THD is $16.86 \%$ and $24.4 \%$ compared to the regular operation mode $(\mathrm{THD}=13.83 \%)$.

For the fault of battery $E_{2}$ and $E_{3}$, their THD values are practically close: $19.15 \%$ and $19.90 \%$. To overcome this situation, the fundamental amplitude, STD and RMSE have been used. For type II fault of battery $E_{2}$ or $E_{3}$, these parameters are respectively equal to $(90.35 \mathrm{~V}, 65.05,24.05 \%)$ and $(84.67 \mathrm{~V}, 61.04$, $28.72 \%)$.

\section{Features Extraction Results for Type III Fault}

In this part, features have been extracted from the output voltage of the 9-level inverter under a type III fault. Table VII illustrates the different values of the selected parameters.

For this type of fault in a 9-level inverter, Table VII shows a remarkable difference in all features except for the mean value, which remains null. For the case of fault of the first three batteries $\left(E_{1}, E_{2}\right.$, and $\left.E_{3}\right)$, one can note that the values of each parameter vary (increase or decrease) for a given feature compared to the regular operation mode. This is to say that such a fault is easily detected. For the localisation purpose, the THD and RMSE increase from fault in the battery $E_{1}$ to $E_{3}$. The intermediate values of THD and RMSE allow concluding that the battery $E_{2}$ is defected. In addition, fault in the battery $E_{1}$ is identified by a higher value of the fundamental amplitude $(50.96 \mathrm{~V})$, which decreases to $13.85 \mathrm{~V}$ and $2.49 \mathrm{~V}$ for a fault in the 
Table. VII

FEATURES OF THE 9-LEVEL INVERTER UNDER TYPE III FAULT

\begin{tabular}{c|c|c|c|c|c}
\hline $\begin{array}{c}\text { Operation } \\
\text { with and without } \\
\text { type III fault }\end{array}$ & $\begin{array}{c}\text { THD } \\
(\boldsymbol{\%})\end{array}$ & $\begin{array}{c}\mathbf{A}_{\mathbf{f}} \\
(\mathrm{V})\end{array}$ & $\begin{array}{c}\mathbf{a}_{\mathbf{0}} \\
(\boldsymbol{\%})\end{array}$ & $\mathbf{S T D}$ & $\begin{array}{c}\text { RMSE } \\
(\boldsymbol{\%})\end{array}$ \\
\hline Without & 13.83 & 120 & 0 & 85.64 & 0 \\
\hline$E_{1}$ & 113.52 & 50.96 & 0 & 54.51 & 36.35 \\
\hline$E_{2}$ & 274.96 & 13.85 & 0 & 28,66 & 66.54 \\
\hline$E_{3}$ & 684.09 & 2.49 & 0 & 12.17 & 85.79 \\
\hline$E_{4}$ & - & 0 & 0 & 0 & 100 \\
\hline
\end{tabular}

battery $E_{2}$ and $E_{3}$, respectively. For the case of the last battery $\left(E_{4}\right)$, almost all the parameters are null for the output voltage with the exception of RMSE (100\%) and the THD. Therefore, for a right diagnosis, it would be wise to take into account the phase-to-phase voltage.

\section{E. Features Extraction Comparison}

From the obtained results of the proposed diagnostic method, it is possible to distinguish between regular operation mode (without fault) and that in the presence of a type I, II or III fault. This distinction is ensured by the use of the vector [THD, $A_{f}$, $\left.a_{0}, \mathrm{STD}, \mathrm{RMSE}\right]$. One can recall that obtaining a non-null mean value, $a_{0}$, of the voltage signal, means that a type I fault is faced. However, a null mean value, of this, implies a type II or III fault. Parameters, other than the average value, make possible distinguish between these last two types of fault. In addition to the mean value $a_{0}$, two parameters (THD and $A_{f}$ ) are largely sufficient, in the actual case, to separate between the different types or at least between those of II and III, as illustrated in Fig. 8.

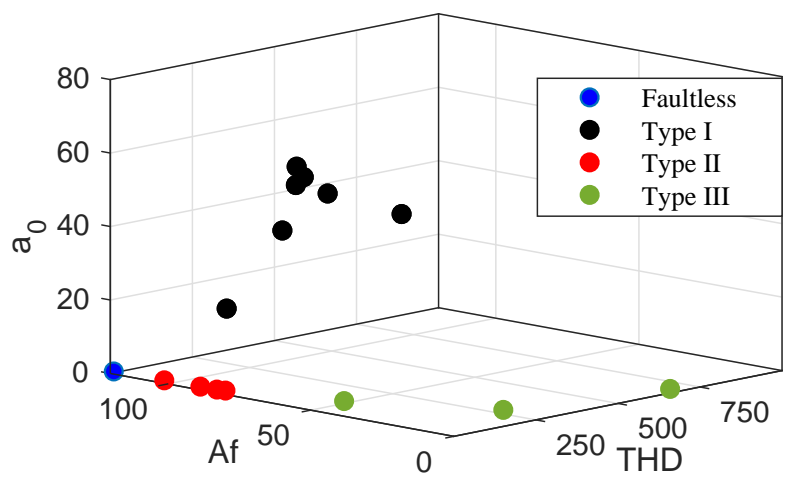

Fig. 8: Parameters distribution with respect to the type of faults for 9-level inverter

Regular operation is indicated by the blue dot. Likewise, the three assemblies presenting the three types of faults are isolated from each other. Since the features round up in separated groups in Fig. 8, the proposed method confirms the absence of correlation between the different types of faults considered. In general, the more uncorrelated the features, the better the classifier performance, which improves the identification process.

\section{CONCLUSion}

This paper dealt with the diagnosis of CHBMI under typical faults where their effects have been examined. First, fault in one of the controllable components has been considered, in which an open-fault case has been selected (Type I). Then, DC link faults have been studied for defected (Type II) and disconnected (Type III) battery. Simulations show the possibility to visually distinguish the fault features from the output voltage signal compared to the regular one. Based on the obtained results, a diagnostic method has been proposed using THD, $A_{f}$ (amplitude of the fundamental), $a_{0}$ (mean value), STD (standard deviation) and RMSE (the mean square error) of the output voltage signal. The first three parameters are largely sufficient to distinguish between the three types of faults. This is due to the total lack of correlation between these faults. The location of faults is done by a classification according to their THD. Faults in switches with the same THD order have been classified in the same group. The other parameters allow further decision between the groups formerly considered. The three types of faults can be identified since the selected features are round up in separated groups. Such findings and the proposed technique might be used to extract a general fault diagnosis method to detect and locate the fault in higher level CHBMIs. The diagnostic results and the information on the identified faulty switches in multilevel converters can help the reduction of the downtime cost of industrial power electronic systems.

\section{REFERENCES}

[1] P. Lezana, J. Pou, T. Meynard, J. Rodriguez, S. Ceballos and F. Richardeau, , "Survey on fault operation on multilevel inverters", IEEE Trans.Indus. Elect., vol. 57, no. 7, pp. 2207-2218, Jul. 2010. https://doi.org/10.1109/TIE.2009.2032194

[2] H. Mhiesan, Y. Wei, Y.P. Siwakoti and H.A. Mantooth, "A FaultTolerant Hybrid Cascaded H-Bridge Multilevel Inverter", IEEE Trans. Power Elect., vol. 35, no. 12, pp. 12702-12715, Dec. 2020. https://doi.org/10.1109/TPEL.2020.2996097

[3] G. Sani Shehu, A. Bala Kunya, I. Shanono and T. Yalcinoz, "A Review of Multilevel Inverter Topology and Control Techniques", International Journal of Automation and Control, vol. 4, no. 3, pp. 233-241, Jun. 2016. https://doi.org/10.1109/MEPCON.2017.8301344

[4] Grain Adam, S.J. Finney, A.M. Massoud and B. Williams, "Capacitor Balance Issues of the Diode-Clamped Multilevel Inverter Operated in a Quasi Two-State Mode", IEEE Trans. Indus. Elect., vol. 55, no. 8, pp. 3088-3099, Sep. 2008. https://doi.org/10.1109/TIE.2008.922607

[5] J.O. Estima and A.J.M. Cardoso, "A new algorithm for realtime multiple open-circuit fault diagnosis in voltage-fed PWM motor drives by the reference current errors," IEEE Trans. Indus. Elec., vol. 60, no. 8, pp. 3496-3505, Aug. 2013. https://doi.org/10.1109/TIE.2012.2188877

[6] M.A.S.K. Khan and M. Azizur-Rahman, "Development and implementation of a novel fault diagnostic and protection technique for IPM motor drives," IEEE Transactions on Industrial Electronics, vol. 56, no. 1, pp. 85-92, Jan. 2009. https://doi.org/10.1109/TIE.2008.2004662

[7] A. Anand, A. Vinayak, N. Raj, G. Jagadanand and S. George, "A Generalized Switch Fault Diagnosis for Cascaded H-Bridge Multilevel Inverters Using Mean Voltage Prediction", IEEE Trans. Indus. Apps., vol. 56, no. 2, pp. 1563-1574, Mar./Apr. 2020. https://doi.org/10.1109/TIA.2019.2959540 
[8] J.S. Lee and K.B. Lee, "An Open-Switch Fault Detection Method and Tolerance Controls Based on SVM in a Grid-Connected T-Type Rectifier With Unity Power Factor," IEEE Trans. Indus. Elect., vol. 61, no. 12, pp. 7092-7104, Dec. 2014. https://doi.org/10.1109/TIE.2014.2316228

[9] S. Khomfoi and L. M. Tolbert, "Fault Diagnosis and Reconfiguration for Multilevel Inverter Drive Using AI-Based Techniques," IEEE Trans. Indus. Electronics, vol. 54, no. 6, pp. 2954-2968, Dec. 2007. https://doi.org/10.1109/TIE.2007.906994

[10] J.S. Lee and K.B. Lee, "A Fault Detection Method and a Tolerance Control in a Single-Phase Cascaded H-bridge Multilevel Inverter," IFAC PapersOnline, vol. 50, no. 1, pp. 7819-7823, Jul. 2017. https://doi.org/10.1016/j.ifacol.2017.08.1058

[11] W. Qiao and D. Lu, "A survey on wind turbine condition monitoring and fault diagnosis-Part I: Components and subsystems", IEEE Trans. Indus. Elect., vol. 62, no. 10, pp. 6536-6545, Oct. 2015. https://doi.org/10.1109/TIE.2015.2422112

[12] U. Choi, F. Blaabjerg and K. Lee, "Study and handling methods of power IGBT module failures in power electronic converter systems", IEEE Trans. Power Elect., vol. 30, no. 5, pp. 25172533, May 2015. https://doi.org/10.1109/TPEL.2014.2373390

[13] M.L. Hossain, A. Abu-Siada and SM. Muyeen, "A hybrid multilevel power electronic inverter and fault location identification of switching devices", IEEE 2018 Condition Monitoring and Diagnosis (CMD), pp. 1-4, 2018. https://doi.org/10.1109/CMD.2018.8535618

[14] Y.J. Ko, K.B. Lee, D.C. Lee, and J.M. Kim, "Fault diagnosis of three-parallel voltage-source converter for a high power wind turbine," IET Power Electronics, vol. 5, no. 7, pp. 1058-1067, Aug. 2012. https://doi.org/10.1109/ECCE.2011.6063863

[15] W.S. Im, J.M. Kim, D.C. Lee, and K.B. Lee, "Diagnosis and fault-tolerant control of three-phase ac-dc PWM converter systems," IEEE Transactions on Industrial Applications, vol. 49, no. 4, pp. 1539-1547, Jul./Aug. 2013. https://doi.org/10.1109/TIA.2013.2255111

[16] O. Kherif, Y. Benmahamed, D. Maadjoudj, M. Teguar, M. Bounabi and C. Larbes, "Fault Diagnosis Method for Cascaded H-bridge Multilevel Inverters under Switching Device Failure," 2019 19th Int. Symp. Electromagnetic Fields in Mechatronics, Electrical and Electronic Engineering (ISEF), Nancy, France, France, 29-31 Aug. 2019. https://doi.org/10.1109/ISEF45929.2019.9096978

[17] J. Amini and M. Moallem, "A fault-diagnosis and fault-tolerant control scheme for flying capacitor multilevel inverters", IEEE Trans. Indus. Elect., vol. 64, no. 3, pp. 1818-1826, Mar. 2017. https://doi.org/10.1109/TIE.2016.2624722

[18] M. Ardakani, M. Askarian, A. Shokry, et al., "Optimal features selection for designing a fault diagnosis system", Computer Aided Chemical Engineering, vol. 38, pp. 1111-1116, Jun. 2016. https://doi.org/10.1016/B978-0-444-63428-3.50190-9

Omar KHERIF received a M.Eng. and Ph.D. degrees in electrical engineering from the Ecole Nationale Polytechnique (ENP) in 2015 and 2019, respectively. He was a mathematicalanalysis teacher with ENP from 2016 to 2018. He was also researcher with the Laboratoire de Recherche en Electrotechnique (LRE) of the ENP, where he co-supervised several M.S. theses. He is currently a KTP Associate with Cardiff University and a Technical Consultant with Kingsmill Industries Ltd (UK). His main interests are in high voltage engineering, electromagnetic transients, earthing and power system protection. Dr
Kherif is a member of IEEE and some of IEEE societies since 2017.

Tahar ZEBBADJI Tahar received his Engineer Diploma from the Ecole Nationale Polytechnique (ENP) of Algiers in 1984 and then obtained the Master degree from the University of Colorado, Boulder, USA in 1987. He is currently a senior lecturer in the department of electrical engineering with the Ecole Nationale Polytechnique of Algiers. He is also a member of the research team of the Laboratoire de Recherche en Electrotechnique (LRE), ENP, Algiers. His main area of interests includes the modelling and control of power electronics.

Youcef GHERBI was born on April 23rd, 1997 in Algiers. He received a M.S. and Engineer degrees in Electrical Engineering from Ecole Nationale Polytechnique (ENP) in 2020. He was also researcher with the Laboratoire de Recherche en Electrotechnique of the ENP. Mr Gherbi is currently an Instrumentation \& Control Engineer in the Oil \& Gas industries. His main research interests are in power electronics and renewable energies.

Mohamed Larbi AZZOUZE received a M.S. and Engineer degrees in electrical engineering from Ecole Nationale Polytechnique (ENP) in 2020. He was also researcher with the Laboratoire de Recherche en Electrotechnique of the ENP. Mr AZZOUZE is currently a MSc student in Global Purchasing and Supply Chain Management at Audencia Business School. His main research interests are in power electronics and diagnosis.

Madjid TEGUAR received the degree in electrical engineering, the master's degree, and the Ph.D. degree in high voltage engineering from the École Nationale Polytechnique (ENP) of Algiers, in 1990, 1993, and 2003, respectively. He is currently a Professor of Electrical Engineering with ENP. His research interests include insulation systems, insulation coordination, earthing of electrical power systems, and polymeric cables insulation. 